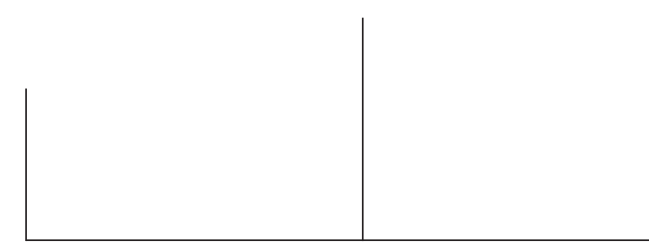

Rev. Latinoam. Psicop. Fund., III, 1, 158-163

\title{
Bleuler e a invenção da esquizofrenia
}

\author{
Mário Eduardo Costa Pereira
}

Em 1911, Eugen Bleuler publica sua monumental monografia intitulada "Demência precoce ou o grupo das esquizofrenias"1, que fundaria a visão científica contemporânea sobre essas psicoses.

No presente número, a Revista Latinoamericana de Psicopatologia Fundamental apresenta a tradução da primeira parte da seção V daquele trabalho, que trata especificamente do "Conceito da enfermidade”. A leitura desse texto, de importância maior para a história da psicopatologia, permitirá situar alguns elementos centrais da contribuição de Bleuler à constituição da categoria “esquizofrenia”.

Eugen Bleuler nasceu em 1857 na pequena cidade suíça de Zollikon, a mesma onde um século mais tarde, Martin Heidegger proferiria durante quase uma década, a convite de Medard Boss, seus famosos seminários sobre psiquiatria.

Tendo feito sua formação médica e sua iniciação psiquiátrica na Suíça, Bleuler desloca-se a Paris para prosseguir seus estudos com Charcot e Magnan e, em seguida, a Munique, no Instituto Von Gudden. Finalmente, retorna a Zurique para concluir seu internato na Clínica Universitária de Burghölzli, sob a direção de Auguste Forel².

1. E. Bleuler (1911). Demencia precoz: el grupo de las esquizofrenias. Buenos Aires: Paidós.

2. Cf. J. Postel \& C. Quetel (orgs.). Nouvelle histoire de la psychiatrie. Toulouse: Privat, 1983, pp. 588-589. 


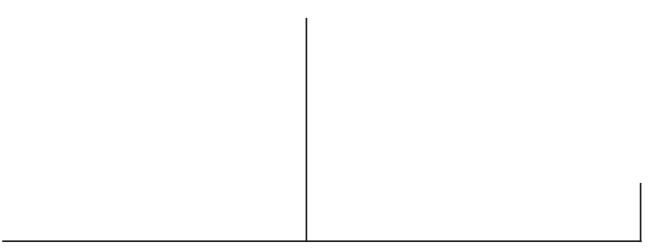

Em 1898, Bleuler assume a cátedra de psiquiatria da Universidade de Zurique, sucedendo a Forel no Burghölzli. Sob sua direção, essa instituição adquiriria reputação mundial, tendo lá trabalhado como seus assistentes nomes como os de Carl Gustav Jung, Karl Abraham, Ludwig Binswanger e Eugène Minkowski.

Seu interesse pela psicanálise foi transitório, mas marcou profundamente seu trabalho psiquiátrico, em particular sua abordagem da demência precoce. Já em 1896 Bleuler publica uma resenha (qualificada por Ernest Jones como “ambivalente”) dos Estudos sobre a histeria no Nünchner medizinische Wochenschrift, considerando a obra de Breuer e Freud como "uma das mais importantes contribuições dos últimos anos para o campo da psicologia normal (sic) ou patológica”3.

Em sua biografia de Freud, Ernest Jones refere que, no outono de 1904, o mestre de Viena fora informado que Bleuler e seu grupo vinham trabalhando com a psicanálise e descobrindo novas aplicações para ela. Jung, na época o principal assistente de Bleuler, era o líder desse movimento de aproximação da psiquiatria à psicanálise. Ele lera A interpretação dos sonhos e, baseado nos princípios lá expostos, desenvolveu alguns testes de associação de idéias, de modo a demonstrar experimentalmente a existência de elementos recalcados, organizados sob a forma de "complexos afetivos" (empregando de forma modificada o termo "complexo", anteriormente usado por Ziehen).

Em 1906, Jung publica seus Estudos de diagnóstico de associação e, em seguida, A psicologia da demência precoce, livro que teria profunda influência no pensamento de Bleuler.

Na verdade, trabalhando em uma clínica de pacientes psiquiátricos graves, Bleuler dispõe de um vasto material clínico para estudar os fenômenos psicóticos, em particular a chamada “demência precoce”, segundo a nomenclatura kraepeliniana dominante na época. Seu propósito era o de definir, para além das meras constelações sintomatológicas regulares estabelecidas por Kraepelin, o fundamento psicopatológico daquela afecção, que faria sua unidade apesar das diferentes formas de apresentação.

A particularidade de seu método consistia na aplicação dos testes de associação desenvolvidos por Jung, em pacientes com diagnóstico de demência precoce, de modo a evidenciar os elementos primários à base da psicopatologia daquelas psicoses. O resultado seria uma verdadeira revolução na doutrina kraepeliniana, terminando por superá-la em diversos planos fundamentais, inclusive no terminológico.

A teorização de Kraepelin sobre a demência precoce foi se constituindo gradualmente, ao longo das sucessivas edições de Tratado de psiquiatria, notadamente a partir da quinta, datada de 1896. É nessa, justamente, que será introduzida a dimensão evolutiva como critério nosográfico fundamental na

3. Cf. E. Jones. A vida e a obra de Sigmund Freud, vol. I. Rio de Janeiro: Imago, 1989, p. 258. 
metodologia kraepeliniana. Até então, a ênfase era colocada na descrição sistemática e rigorosa dos casos clínicos e na classificação destes, segundo suas semelhanças e diferenças formais. Havia a recusa explícita de se intentar qualquer busca de significação aos sintomas, restringindo-se escrupulosamente apenas aos dados objetivos obtidos no plano clínico.

Com a introdução da dimensão evolutiva, as chamadas "doenças mentais" deveriam ser delimitadas não apenas em função de suas características atuais, mas em função também de seu desenrolar diacrônico característico, ou seja, segundo sua "história natural".

Naquela edição já figurava o termo "demência precoce", mas ainda restrito à concepção herdada de Morel: um quadro de empobrecimento intelectual importante que se instalava a partir da adolescência ou no início da idade adulta.

É a sexta edição, datada de 1899, que trará as modificações mais significativas. Nela, o termo "demência precoce” passará a nomear uma doença única que agrupa formas clínicas bastante díspares e que têm em comum o fato de iniciarem em geral cedo na vida, e conduzirem de maneira inexorável a um estado de embrutecimento intelectual (Verblödung) irreversível. O critério evolutivo estava definitivamente embutido na própria definição da doença.

Com essa perspectiva, Kraepelin toma condições clínicas bastante díspares e até então consideradas como entidades independentes e lhes confere unidade psicopatológica segundo um início precoce e uma evolução a um estado terminal comum. Assim, a catatonia, descrita por Kahlbaum entre 1863 e 1874; a hebefrenia, estabelecida por Heckel (um discípulo de Kahlbaum) em 1871 e a paranóia, passam a ser consideradas como formas clínicas da demência precoce.

Segundo a visão kraepeliniana, a demência precoce constitui uma entidade mórbida específica, uma enfermidade no sentido médico e supõe que sua causa seria uma auto-intoxicação por substâncias de origem sexual.

Rapidamente, o pensamento de Kraepelin impõe-se à psiquiatria européia e vai tomando a legitimidade de um verdadeiro sistema nosográfico capaz de lançar luz ao campo tradicionalmente obscuro da clínica das psicoses.

Não obstante, grande número de críticas e objeções foram levantadas contra as proposições kraepelinianas. Em primeiro lugar, muitos consideravam que a noção de "demência precoce" era excessivamente ampla, reunindo sob si condições clínicas muito díspares. Além disso, tratava-se de uma categoria fundada sobre o estado terminal da doença, o que obrigaria o clínico a manter o diagnóstico em suspensão até que se instalasse um estado já sem recuperação.

Muitos contestaram o fato de que a Verblödung em questão não era uma verdadeira demência, mas um grave empobrecimento da personalidade em função da evolução crônica da patologia, fato que, diga-se de passagem, nunca foi contestado por Kraepelin. 
Particularmente problemática era a forma paranóide ${ }^{4}$ da demência precoce kraepeliniana pois reunia a uma só vez os delírios persecutórios de evolução crônica, tão caros à tradição francesa e as formas delirantes alucinatórias. A psiquiatria francesa sempre sustentou a independência psicopatológica dos delírios persecutórios crônicos em relação às demais formas de psicose, entre outros motivos justamente por que estes não conduzem, em geral, a nenhuma deterioração importante da personalidade fora da esfera limitada do delírio. Tal contestação é aceita por Kraepelin e incorporada à oitava edição de seu Tratado, que passará a restringir a forma paranóide aos delírios persecutórios acompanhados de outros fenômenos psicóticos, notadamente as alucinações. O termo "paranóia" passará a ter a significação atual, próxima da definição dada por Sérieux e Capgras aos delírios de interpretação, ou seja, delírios crônicos, de caráter persecutório, com manutenção das demais esferas da vida psíquica.

Kraepelin também era criticado por ter deixado completamente de lado a análise psicológica na constituição da categoria de demência precoce, o que na França, desde Esquirol, fazia parte integrante de qualquer abordagem dos fenômenos psicóticos.

Diante desse quadro, Bleuler vai se dedicar ao estudo da demência precoce, só que dessa vez munido do instrumental teórico e metodológico fornecido pela psicanálise freudiana. De Jung, ele já recebera a noção, expressa em A psicologia da demência precoce, segundo a qual o que faz a especificidade dessa psicopatologia não é propriamente a qualidade dos complexos, mas a extrema fixação que o sujeito tem a estes, instalando-se uma situação insuportável de absorção de todos os interesses do indivíduo em seu próprio mundo psíquico, isolando-se dos laços afetivos, da vida social e do próprio contato com a realidade. A noção bleuleriana de "esquizofrenia" buscaria, justamente, colocar em relevo aquele que seria o fenômeno nuclear desses estados mentais, a ruptura, a cisão do eu, em função do rompimento dos vínculos associativos que assegurariam um funcionamento unitário da personalidade.

Bleuler começa a empregar o neologismo esquizofrenias desde 1906, sendo que esse uso do plural já é uma forma de acentuar sua ruptura em relação ao pensamento kraepeliniano. Não se trataria de uma única afecção, como supunha Kraepelin, mas de um grupo ainda indeterminado de condições com um núcleo psicopatológico comum.

Existe, entretanto, um esforço por reconhecer que a demência precoce descrita por Kraepelin constitui um verdadeiro conceito de enfermidade mental, tratando-se, na verdade, de substituir os critérios empírico-evolutivos por critérios propriamente

4. Cf. P. Bercherie. Histoire et structure du savoir psychiatrique: les fondements de la clinique - I. Tournai: Editions Universitaires, 1991. 


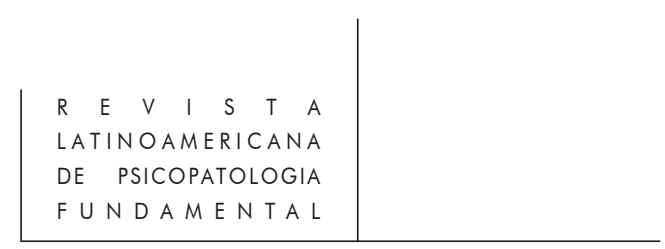

psicopatológicos, ou seja, que suponham uma teoria da doença. Estamos, pois, diante de um esforço muito estranho, uma vez que Bleuler apresenta-se como defensor das idéias de Kraepelin, ao mesmo tempo que seu conceito de "esquizofrenias" contesta os próprios fundamentos dessas proposições.

Em primeiro lugar, Bleuler distingue os "sintomas primários”, que são relativos à etiologia, dos "sintomas fundamentais", relativos ao diagnóstico.

Os sintomas primários são aqueles a partir dos quais a enfermidade se instala. Segundo Bleuler, estes são irredutíveis pela compreensão psicológica. Tratam-se de manifestações diretas e incompreensíveis do processo mórbido. Na seção da monografia sobre "o grupo das esquizofrenias", é dito explicitamente que a origem desses sintomas ainda é obscura, mas que "não é absolutamente necessário supor a presença de um processo patológico físico. É concebível que toda sintomatologia esteja psiquicamente determinada”. Tal posição é matizada a seguir, deixando margem a uma interação de fatores físicos e psíquicos.

Para Bleuler, o sintoma primário por excelência é a clivagem das associações entre as funções psíquicas, rompendo-se a unidade do eu e colocando em jogo a necessidade de restituição da integração perdida, tarefa expressa pelos sintomas

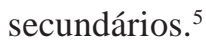

Outros sintomas primários seriam os estados de obnubilação, as oscilações afetivas e a predisposição a alucinações.

Os sintomas secundários, por sua vez, como vimos, representam tentativas por vezes desesperadas de se fazer frente a um estado psíquico desesperador de ruptura da unidade do eu: "Por uma parte, o relaxamento das associações tem por resultado a abertura de vias errôneas de pensamento, que se apartam da experiência; e por outra, o paciente se vê obrigado a operar com fragmentos de idéias”. Entre estes estão a alteração do fluxo do pensamento, a ambivalência afetiva, os delírios e as alucinações.

A outra oposição é a que separa os sintomas fundamentais dos sintomas acessórios. Aqueles visam superar o inconveniente clínico introduzido pela perspectiva evolutiva: buscam-se sintomas que estejam presentes em todas as formas de esquizofrenia e em qualquer momento de sua evolução. São sintomas fundamentais o autismo, a ambivalência afetiva, as alterações da afetividade e os próprios distúrbios das associações. Já os sintomas acessórios podem não estar presentes em todos os casos e/ou em todos os momentos e são representados pelos delírios, pelas alucinações e pelos quadros catatônicos, entre outros.

Dessa forma, a determinação dos sintomas primários decorre, na obra de Bleuler, por um processo de interpretação dos sintomas e de uma concepção global

5. Cf. J. Garrabe. Histoire de la schizophrénie. Paris: Seghers, 1992. 


\section{CLÁSSICOS DA}

PSICOPATOLOGIA

da psicopatologia, afastando-se da descrição objetiva de Kraepelin. Além disso, a deterioração terminal é apenas um dos destinos possíveis da esquizofrenia, não sendo mais considerada como a via inexorável final e o ponto de articulação comum entre as diferentes formas clínicas.

No texto aqui traduzido, veremos Bleuler realizar um grande esforço no sentido de demonstrar que a demência precoce, de Kraepelin, constitui um autêntico conceito de enfermidade mental. Para isso, mostra que a profusão de categorias e descrições de estados psicóticos que reinavam até Kraepelin ocorriam, pois os autores acreditavam que a mera descrição minuciosa do processo clínico em questão era suficiente para criar uma entidade nosológica. Bleuler demonstra o caráter arbitrário de tal procedimento e indica como Kraepelin tentou dar uma consistência psicopatológica para a demência precoce pela introdução do critério evolutivo.

Contudo, Bleuler acabará por indicar os limites desse procedimento kraepeliniano e por introduzir sua própria perspectiva visando a circunscrição dos fenômenos primários, correlativa de uma teoria psicopatológica da esquizofrenia. 